\title{
Relationship between comorbidities and treatment decision-making in elderly hip fracture patients
}

\author{
Jinxing Wei ${ }^{1} \cdot$ Li Zeng $^{2} \cdot$ Shitong $\mathrm{Li}^{1} \cdot$ Fang Luo ${ }^{1}$ Z Zhou Xiang ${ }^{1} \cdot$ Qunfang Ding ${ }^{1}$
}

Received: 29 October 2018 / Accepted: 16 January 2019 / Published online: 16 April 2019

(c) Springer Nature Switzerland AG 2019

\begin{abstract}
Background Elderly patients are at a higher risk for hip fracture. Moreover, hospitalized elderly patients with hip fracture are vulnerable to adverse outcomes including higher mortality rate and long-term disability. Treatment decision-making with respect to surgical procedure and perioperative management of these patients is typically challenging owing to the presence of multiple comorbid conditions.

Aims The purpose of this study was to investigate the relationship between comorbidities in elderly patients with hip fracture and the treatment decision-making.

Methods 884 geriatric patients (age $\geq 60$ years) with hip fracture were included. Comorbidities related to age were measured using the Charlson Co-morbidity Index (CCI) and age-adjusted CCI. The CCI of each geriatric hip fracture patient was calculated based on data retrieved from the medical records. The relationship of CCI and age-adjusted CCI with surgical procedure, time-to-surgery, length of hospital stay, and perioperative management (transfusion, anti-coagulation, and analgesia) was assessed.

Results Mean age of patients was $78.01 \pm 8.62$ years. The mean CCI was $0.79 \pm 0.036$; the mean age-adjusted CCI was $4.15 \pm 0.047$. The CCI was significantly associated with time-to-surgery $(P=0.004)$, surgical treatment $(P<0.001)$, and transfusion $(P=0.023)$. The age-adjusted CCI was significantly associated with surgical treatment $(P<0.001)$, analgesia $(P=0.003)$ and transfusion $(P<0.001)$. The length of hospital stay was associated with both $\mathrm{CCI}(P=0.041)$, age-adjusted CCI $(P=0.002)$, and hypertension $(P=0.012)$. Hospital expenses showed a significant association with CCI $(P=0.000)$, age-adjusted CCI $(P=0.029)$, osteoprosis $(P=0.007)$, and hypertension $(P=0.001)$.

Conclusion In this study, comorbidities were positively associated with surgical procedure and perioperative management of elderly patients with hip fracture.
\end{abstract}

Keywords Aging $\cdot$ Hip fracture $\cdot$ Comorbidity $\cdot$ Charlson Comorbidity Index (CCI) $\cdot$ Treatment decision-making

Jinxing Wei and Li Zeng contributed equally to the work.

Electronic supplementary material The online version of this article (https://doi.org/10.1007/s40520-019-01134-5) contains supplementary material, which is available to authorized users.

Qunfang Ding

dingqf2013@126.com

1 Department of Geriatrics, West China Hospital, Sichuan University, NO. 37 GuoXue Road, Chengdu 610041, Sichuan, China

2 Department of Geriatrics, Sichuan Provincial People's Hospital, Chengdu 610072, China

\section{Introduction}

Hip fractures are a major cause of mortality and disability in the elderly population. Moreover, it increases the burden on caregivers, families, as well as the society at large. The number of geriatric patients with hip fracture has dramatically increased over the last decade [1-3]. Hip fractures are the second most common cause of hospitalization of elderly patients, with an estimated annual cost of over $\$ 650$ million $[3,4]$. Elderly patients with hip fractures constitute the most vulnerable group among hospitalized patients, and their clinical outcomes are closely linked to the quality of care [5].

In the last decade, several studies have sought to identify factors that influence the clinical outcomes of these patients $[6,7]$. Timing of surgery as well as other medical factors 
have been shown to influence the clinical outcomes of geriatric patients with hip fracture [8]. Surgical delay may lead to an increase in mortality and adverse clinical outcomes such as infection and pressure sores $[9,10]$. Therefore, it is important to evaluate the patient's condition for making an individual management plan. Clinical guidelines recommend that reparative surgery should be performed within $24-48 \mathrm{~h}$ of hospital admission; $[7,8]$ however, adequate perioperative assessment of the patient condition including evaluation of comorbid diseases is necessary to develop an optimal treatment plan for elderly patients.

When compared with elderly hip fracture patients without comorbidities, those with comorbidities may accept less-aggressive medical therapy, and experience extended duration of hospitalization, decreased quality of life, and increased health care costs. This is because prolonged immobilization is likely to increase the incidence of urinary and pulmonary complications [11]. Thus, the combination of advanced age and presence of comorbidities in elderly patients with hip fracture presents a considerable challenge with respect to surgical decision-making and perioperative management $[12,13]$.

The primary objective of this study was to investigate the association between comorbidities [as assessed by Charlson Comorbidity Index (CCI) and age-adjusted CCI] [14, 15] and treatment decision-making including the surgical procedure and perioperative management in elderly patients with hip fracture.

\section{Methods}

\section{Study design and population}

This was a cross-sectional observational study of patients with femoral neck fracture or intertrochanteric fracture who were admitted to the West China Hospital of Sichuan University, Chengdu, China between January 2011 and December 2015 . The inclusion criteria were: patients aged $\geq 60$ years with femoral neck fracture or intertrochanteric fracture diagnosed by computed tomography (CT) or X-ray for the first time; presence of comorbid conditions (Table 2); time interval from fracture to hospitalization $\leq 15$ days. The exclusion criteria were: patients with pathological fracture; incomplete medical records; patients with a prior history of hip fracture, and previous surgical management.

The study was approved by the Biomedical Ethics Committee of the West China Hospital of Sichuan University. Written informed consent was obtained from all subjects.

\section{Data collection}

This study was a purely descriptive study of consecutive patients who were registered in the information system of the West China hospital. Data pertaining to the following variables were collected from the medical records: established diagnosis, age at admission, gender, cause of fracture, type of fracture, time-to-surgery, length of hospital stay, hospitalization expenses, comorbid conditions, treatment details, and postoperative complications.

Data collection was performed by postgraduate medical students at the West China Clinical Medical School, West China Hospital, Sichuan University. All data collectors underwent training for data extraction and data entry.

\section{Assessment of comorbidities}

The Charlson Comorbidity Index (CCI) was used to evaluate patient comorbidity. The CCI incorporates the number of pre-existing comorbid conditions and their severity [14, 15]. It represents the sum of weighted index for different subset of conditions: one point was awarded for myocardial infarction, congestive heart failure, peripheral vascular disease, cerebrovascular disease (except hemiplegia), dementia, chronic pulmonary disease, connective tissue disorders, ulcer disease, mild liver disease, and diabetes without complications. Two points were awarded for diabetes with end-organ damage, hemiplegia, moderate or severe renal disease, or any malignancy including leukemia, lymphoma, diabetes with chronic complications, and solid tumors (non metastatic). Three points were awarded for moderate or severe liver disease, while six points were awarded for acquired immune deficiency syndrome (AIDS) and metastatic solid tumors. Higher scores correspond to increased risk of mortality. The total score was calculated for each patient; based on the total score, the study population was classified into four ordinal categories: $0,1-2$, $3-4, \geq 5$ points. In addition, age-adjusted CCI was also calculated, wherein one point was awarded for each decade of life after the age of 50 years [16].

Hypertension and osteoporosis, which are not included in the CCI, were also included in the analysis. Hypertension was defined as a systolic blood pressure $>140 \mathrm{mmHg}$ and/or diastolic blood pressure $>90 \mathrm{mmHg}$ or by history of antihypertensive therapy. Patients who fulfilled one out of the following three criteria were considered osteoporotic: (1) occurrence of adulthood hip or vertebral fracture in the absence of major trauma; (2) $T$ score $<-2.5$ on dual energy X-ray absorptiometry (DXA); (3) presence of fragility fractures of proximal humerus, pelvis, or distal forearm with $-2.5<T$ score $<-1.0$. 
Data pertaining to chronic diseases that were already diagnosed were obtained from the medical records. The differential diagnosis had been completed in the past.

\section{Statistical analysis}

Continuous variables are expressed as mean \pm standard deviation (SD) and compared using Student's $t$ test. Categorical variables are expressed as percentages and compared using the Chi-squared test. The CCI and other comorbidities were used as independent variables. Binary logistic regression models were used to examine the relationship of CCI with complications, surgical choice, time-to-surgery, transfusion, anti-coagulation, analgesia, and complications after hip fractures. Linear regression analysis was performed to examine the relationship of length of hospital stay and hospital expenses with CCI, age-adjusted CCI, osteoporosis, and hypertension. The results are presented as crude and adjusted regression coefficients and 95\% confidence intervals, standardized coefficients, and $P$ values. All statistical tests of significance were two-tailed, and $P$ values $<0.05$ were considered statistically significant. Statistical analyses were performed using SPSS 16.0 statistics software (SPSS Inc. Chicago, IL, USA).

\section{Results}

A total of 884 patients with hip fracture were included in the study (Table 1). Of these $558(66.5 \%)$ were female and $296(33.5 \%)$ were male; the mean age of patients was $78.01 \pm 8.62$ years. A vast majority of the patients had fragility fractures [839 $(95.0 \%)$ patients]. Patients with femoral neck fracture accounted for $60.2 \%$ of the study population. The average CCI and age-adjusted CCI were $4.15 \pm 0.047$ and $0.79 \pm 0.036$, respectively; most of the patients had a CCI in the range of $0-2$ points. Male patients exhibited a tendency for higher CCI than female patients $(P=0.053)$. The age-adjusted CCI for male patients was significantly higher than that for female patients $(P=0.019)$. The mean age-adjusted CCI of patients with intertrochanteric fracture was significantly higher than that of patients with femoral neck fracture $(P=0.010)$ (Table 1$)$.

The prevalence of comorbidities and complications in our study population is presented in Table 2 . Most of the patients scored one point for chronic diseases; there was a high proportion of patients with chronic pulmonary disease (11.65\%) and diabetes without complications (22\%). The prevalence of hypertension and osteoporosis was $45.02 \%$ and $43.67 \%$, respectively. The most common complication after hip fracture was pulmonary infection (18.2\%). The results of univariate logistic regression analysis between age-adjusted CCI, CCI, hypertension, and osteoporosis are presented in Table 3. Both age-adjusted CCI and CCI showed a significant association with higher incidence of pulmonary infection (OR 1.448, $P=0.000,95 \%$ CI $1.287-1.629)$ after hip fracture. The CCI had a tendency to associate with venous thrombosis and urinary tract infection. However, age-adjusted CCI was a predictor of venous thrombosis (OR 1.192, $P=0.024,95 \%$ CI $1.023-1.387$ ) and urinary tract infection (OR 1.286, $P=0.043,95 \%$ CI 1.008-1.639). Additionally, hypertension contributed significantly to the increase in venous thrombosis (OR 1.652, $P=0.036,95 \%$ CI 1.034-2.652). Conversely, osteoporosis was not associated with complications after hip fracture (Table 3).

Table 1 Summary statistics of patient characteristics

\begin{tabular}{|c|c|c|c|c|c|c|c|c|c|}
\hline \multirow[t]{2}{*}{ Variables } & \multirow[t]{2}{*}{ Total $(n=884)$} & \multicolumn{4}{|c|}{ CCI by categories } & \multirow[t]{2}{*}{ Age-adjusted CCI } & \multirow[t]{2}{*}{$P$} & \multirow[t]{2}{*}{$\mathrm{CCI}$} & \multirow[t]{2}{*}{$P$} \\
\hline & & 0 & $1-2$ & $3-4$ & $\geq 5$ & & & & \\
\hline \multicolumn{10}{|l|}{ Gender, $n(\%)$ or mean $\pm \mathrm{SD}$} \\
\hline Male & $296(33.5)$ & $136(30.0)$ & $130(35.8)$ & $26(44.1)$ & $3(42.9)$ & $4.31 \pm 1.46$ & \multirow[t]{2}{*}{0.019} & $0.88 \pm 0.64$ & \multirow[t]{2}{*}{0.053} \\
\hline Female & $588(66.5)$ & $318(70.0)$ & $233(64.2)$ & $33(55.9)$ & $4(57.1)$ & $4.07 \pm 1.48$ & & $0.74 \pm 0.43$ & \\
\hline \multicolumn{10}{|l|}{ Age, $n(\%)$ or mean \pm SD } \\
\hline $60-69$ & $157(17.7)$ & $90(19.8)$ & $55(15.2)$ & $9(15.3)$ & $2(28.6)$ & $2.71 \pm 1.12$ & \multirow[t]{4}{*}{$<0.001$} & $0.71 \pm 1.12$ & \multirow[t]{4}{*}{0.620} \\
\hline $70-79$ & $325(36.8)$ & $163(35.9)$ & $138(38.0)$ & $23(39.0)$ & $1(14.3)$ & $3.79 \pm 1.04$ & & $0.79 \pm 1.04$ & \\
\hline $80-89$ & $329(37.2)$ & $162(35.7)$ & $147(40.5)$ & $18(30.5)$ & $2(28.6)$ & $4.80 \pm 0.57$ & & $0.80 . \pm 1.03$ & \\
\hline$\geq 90$ & $73(8.3)$ & $39(8.6)$ & $23(6.3)$ & $9(15.3)$ & $2(28.6)$ & $5.96 \pm 1.55$ & & $0.90 \pm 1.29$ & \\
\hline \multicolumn{10}{|c|}{ Fracture reasons, $n(\%)$ or mean $\pm \mathrm{SD}$} \\
\hline Trauma fracture & $44(5.0)$ & $22(4.8)$ & $20(5.5)$ & $2(3.4)$ & $0(0)$ & $3.37 \pm 1.23$ & \multirow[t]{2}{*}{0.436} & $0.64 \pm 0.78$ & \multirow[t]{2}{*}{0.089} \\
\hline Fragility fracture & $839(95.0)$ & $432(95.2)$ & $343(94.5)$ & $57(96.6)$ & $7(100.0)$ & $4.18 \pm 0.049$ & & $0.80 \pm 0.037$ & \\
\hline \multicolumn{10}{|c|}{ Fracture patterns, $n(\%)$ or mean $\pm \mathrm{SD}$} \\
\hline Femoral neck fracture & $532(60.2)$ & $171(37.7)$ & $143(39.4)$ & $32(54.2)$ & $5(71.4)$ & $3.94 \pm 1.32$ & \multirow[t]{2}{*}{$<0.001$} & $0.70 \pm 0.98$ & \multirow[t]{2}{*}{0.002} \\
\hline Intertrochanteric fracture & $352(39.8)$ & $283(62.3)$ & $220(60.6)$ & $27(45.8)$ & $2(28.6)$ & $4.47 \pm 1.50$ & & $0.92 \pm 1.18$ & \\
\hline
\end{tabular}


Table 2 Description of the comorbidities and post-hip fracture complications in the study population

\begin{tabular}{|c|c|c|}
\hline Variables & Points & $N(\%)$ \\
\hline \multicolumn{3}{|l|}{ Comorbidities taken into account in the CCI } \\
\hline Chronic pulmonary disease & 1 & $103(11.65)$ \\
\hline Connective tissue diseases & 1 & $20(2.3)$ \\
\hline Congestive heart failure & 1 & $32(3.6)$ \\
\hline Cerebrovascular disease (without hemiplegia) & 1 & $57(6.4)$ \\
\hline Dementia & 1 & 35 (3.9) \\
\hline Diabetes without complications & 1 & $195(22)$ \\
\hline Mild liver disease & 1 & $9(1.0)$ \\
\hline Myocardial infarction & 1 & $4(0.4)$ \\
\hline Peripheral vascular insufficiency & 1 & $2(0.2)$ \\
\hline Ulcer disease & 1 & $3(0.3)$ \\
\hline Diabetes with chronic complications & 2 & $5(0.5)$ \\
\hline Moderate-to-severe renal disease & 2 & $34(3.8)$ \\
\hline Hemiplegia & 2 & $14(1.6)$ \\
\hline Tumor including leukemia and lymphoma & 2 & $38(4.3)$ \\
\hline Hepatopathies at severe stage & 3 & $2(0.2)$ \\
\hline AIDS & 6 & $1(0.1)$ \\
\hline Metastatic cancer & 6 & $1(0.1)$ \\
\hline \multicolumn{3}{|l|}{ Presence of other comorbidities } \\
\hline Hypertension & - & $398(45.02)$ \\
\hline Osteoporosis & - & $386(43.67)$ \\
\hline Complications after hip fracture & - & \\
\hline Venous thrombosis & - & $78(8.8)$ \\
\hline Urinary tract infection & - & $25(2.8)$ \\
\hline Pulmonary infection & - & $161(18.2)$ \\
\hline Delirium & - & $14(1.6)$ \\
\hline Pressure sores & - & $29(3.2)$ \\
\hline
\end{tabular}

CCI Charlson Comorbidity Index, AIDS acquired immune deficiency syndrome

In logistic regression, the CCI remained remarkably associated with time-to-surgery (OR $0.715, P=0.004$, 95\% CI 0.567-0.901), surgical choice (OR 0.759, $P=0.000,95 \%$ CI 0.666-0.867), and transfusion (OR $1.175, P=0.023,95 \%$ CI 1.022-1.350) (Table 4). The age-adjusted CCI showed a significant positive association with surgical choice (OR 0.704, $P=0.000,95 \% \mathrm{CI}$ $0.633-0.783$ ) and transfusion (OR 1.252, $P=0.000,95 \%$ CI 1.122-1.396).

On linear regression analysis, the length of hospital stay was associated with CCI $(B 1.659, P=0.041,95 \%$ CI $0.814-2.503)$, age-adjusted CCI $(B 0.938, P=0.002,95 \%$ CI 0.297-1.580), and hypertension ( $B$ 2.339, $P=0.012$, 95\% CI 0.513-4.164). Hospital expenses showed a significant association with CCI ( $B$ 2963.144, $P=0.000,95 \%$ CI 1336.728-4589.561), age-adjusted CCI ( $B$ 1384.695, $P=0.029,95 \%$ CI 145.561-2623.829), osteoporosis (B 4811.431, $P=0.007$, 95\% CI 1290.779-8332.084), and hypertension $(B$ 5822.974, $P=0.001,95 \%$ CI 2319.887-9326.061) (Table 5).

\section{Discussion}

In the present study, $76.9 \%$ of geriatric patients with hip fracture were not operated during the first $48 \mathrm{~h}$. This is likely attributable to the time required for assessment and stabilization of comorbid diseases. The weight of comorbidities in elderly patients with hip fracture (as assessed by $\mathrm{CCI}$ ) was associated with time-to-surgery in excess of $48 \mathrm{~h}$, which implies that increase in the CCI increased the risk of delayed surgery. However, it showed no significant association with time-to-surgery in excess of $48 \mathrm{~h}$ after adjusting for age. Additionally, the weight of comorbidities in elderly patients with hip fracture (as assessed by age-adjusted CCI) was associated with unavailable operation, increased transfusion, increased hospital stay, and hospital expenses.

To the best of our knowledge, this is the first study that investigated the possible association of comorbidities in elderly patients with hip fracture and their treatment preferences, especially with respect to surgical timing and approach. Several studies have shown that patients with hip fracture who are operated within $48 \mathrm{~h}$ experience better clinical outcomes and functional recovery [17-20]. Moreover, clinical guidelines also recommend that surgery for geriatric patients with hip fracture should be performed within the first $48 \mathrm{~h}$ of hospital admission [21, 22]. A study of Spanish patients older than 65 years with hip fracture, conducted by Sanz-Reig et al. [23] investigated preoperative risk factors for surgical delay of $>2$ days from admission. They found that only $44.1 \%$ of patients were operated within the first 2 days of admission. Moreover, CCI $>2$ (mean CCI: $2.8 \pm 1.8$ ) was independently associated with surgical delay of $>2$ days.

However, in a study of 56,500 patients with hip fracture (public hospitals across 8 Spanish regions during 2002-2005) conducted by Librero et al. [24] early surgery was conducted on $25 \%$ of patients older than 60 years; the time-to-surgery assessed by the Risk Mortality Index was associated with higher mortality, but not with higher chronic comorbidities, male gender, or older age. Hence, comorbidity status was a good preoperative indicator of short-term and long-term mortality risk in geriatric patients with hip fracture [13]. Compared with these two studies [23, 24], only $23.1 \%$ of patients were operated within the first $48 \mathrm{~h}$ of admission, which is a very low percentage. Additionally, the lower average CCI in our study population was likely attributable to the lower average age of patients. In the study by Librero et al., two-thirds of the patients were aged $\geq 80$ years; in another Spanish study, the average age of patients was $83.7 \pm 6.9$ years. The 
Table 3 Results of logistic regression analysis showing the association of complications after hip fracture with age-adjusted CCI, CCI, hypertension, and osteoporosis

\begin{tabular}{|c|c|c|c|c|c|c|c|c|}
\hline & \multicolumn{4}{|c|}{ Age-adjusted CCI } & \multicolumn{4}{|l|}{ CCI } \\
\hline & $B$ & $P$ & Odds ratio & $95 \%$ confidence interval & $B$ & $P$ & Odds ratio & $95 \%$ confidence interval \\
\hline Venous thrombosis & 0.175 & 0.024 & 1.192 & $1.023-1.387$ & 0.176 & 0.069 & 1.193 & $0.986-1.443$ \\
\hline Urinary tract infection & 0.251 & 0.043 & 1.286 & $1.008-1.639$ & 0.237 & 0.119 & 1.268 & $0.941-1.708$ \\
\hline Pulmonary infection & 0.370 & 0.000 & 1.448 & $1.287-1.629$ & 0.262 & 0.000 & 1.300 & $1.126-1.500$ \\
\hline Delirium & 0.160 & 0.355 & 1.173 & $0.836-1.646$ & -0.002 & 0.993 & 0.998 & $0.609-1.636$ \\
\hline \multirow[t]{3}{*}{ Pressure sore } & -0.045 & 0.741 & 0.956 & $0.730-1.251$ & -0.176 & 0.392 & 0.838 & $0.560-1.256$ \\
\hline & \multicolumn{4}{|c|}{ Hypertension } & \multicolumn{4}{|c|}{ Osteoporosis } \\
\hline & $B$ & $P$ & Odds ratio & $95 \%$ confidence interval & $B$ & $P$ & Odds ratio & $95 \%$ confidence interval \\
\hline Venous thrombosis & 0.502 & 0.036 & 1.652 & $1.034-2.652$ & 0.393 & 0.099 & 1.481 & $0.929-2.359$ \\
\hline Urinary tract infection & -0.043 & 0.917 & 0.958 & $0.430-2.135$ & -0.155 & 0.708 & 1.268 & $0.380-1.928$ \\
\hline Pulmonary infection & -0.138 & 0.432 & 0.871 & $0.617-1.230$ & 0.144 & 0.409 & 1.155 & $0.820-1.628$ \\
\hline Delirium & -0.394 & 0.480 & 0.483 & $0.224-2.028$ & 0.259 & 0.631 & 1.296 & $0.451-3.725$ \\
\hline Pressure sore & -0.457 & 0.250 & 0.633 & $0.291-1.378$ & -0.097 & 0.801 & 0.908 & $0.428-1.924$ \\
\hline
\end{tabular}

CCI Charlson Comorbidity Index

Table 4 Logistic regression of the age-adjusted CCI, CCI, and treatments

\begin{tabular}{|c|c|c|c|c|c|c|c|c|c|}
\hline & & \multicolumn{4}{|c|}{ Age-adjusted CCI } & \multicolumn{4}{|l|}{ CCI } \\
\hline & & $B$ & $P$ & Odds ration & $\begin{array}{l}95 \% \text { confidence } \\
\text { interval }\end{array}$ & $B$ & $P$ & Odds ratio & $\begin{array}{l}95 \% \text { confidence } \\
\text { interval }\end{array}$ \\
\hline \multicolumn{10}{|l|}{ Time-to-surgery } \\
\hline$\leq 48 \mathrm{~h}$ & $145(23.1)$ & -0.36 & 0.621 & 0.965 & $0.837-1.112$ & -0.336 & 0.004 & 0.715 & $0.567-0.901$ \\
\hline$>48 \mathrm{~h}$ & 483 (76.9) & & & & & & & & \\
\hline \multicolumn{10}{|c|}{ Whether to operate } \\
\hline Yes & $628(71.0)$ & -0.351 & 0.000 & 0.704 & $0.633-0.783$ & -0.275 & 0.000 & 0.759 & $0.666-0.867$ \\
\hline No & $256(29.0)$ & & & & & & & & \\
\hline \multicolumn{10}{|l|}{ Surgical treatment } \\
\hline Osteosynthesis & $355(56.5)$ & -0.084 & 0.171 & 0.919 & $0.815-1.037$ & -0.139 & 0.104 & 0.870 & $0.736-1.029$ \\
\hline Arthroplasty & $273(43.5)$ & & & & & & & & \\
\hline \multicolumn{10}{|l|}{ Analgesia } \\
\hline Yes & $594(67.2)$ & -0.153 & 0.002 & 0.859 & $0.778-0.947$ & -0.037 & 0.573 & 0.963 & $0.779-0.949$ \\
\hline No & $290(32.8)$ & & & & & & & & \\
\hline \multicolumn{10}{|l|}{ Transfusion } \\
\hline Yes & 194 (21.9) & 0.225 & 0.000 & 1.252 & $1.122-1.396$ & 0.161 & 0.023 & 1.175 & $1.022-1.350$ \\
\hline No & $690(78.1)$ & & & & & & & & \\
\hline \multicolumn{10}{|l|}{ Anti-coagulation } \\
\hline Yes & $544(66.9)$ & -0.044 & 0.361 & 0.959 & $0.896-1.025$ & -0.034 & 0.596 & 0.967 & $0.852-1.096$ \\
\hline No & $342(33.1)$ & & & & & & & & \\
\hline
\end{tabular}

CCI Charlson Comorbidity Index

second potential reason may be the higher proportion of female patients in our study, who had lower average age, average CCI, and average age-adjusted CCI. About $47.6 \%$ female patients in our study had osteoporosis, while the corresponding percentage among male patients was $35.8 \%$ only (Supplementary Table 1); it seems that osteoporosis was a major cause of hip fracture among female patients, while chronic diseases and aging played a more important role in male patients. Therefore, the higher proportion of female patients may have induced lower average CCI and 
Table 5 Correlation of Charlson Comorbidity scores, hypertension, osteoporosis with length of hospital stay and hospital expenses

\begin{tabular}{|c|c|c|c|c|c|c|c|c|}
\hline & \multicolumn{4}{|c|}{ Age-adjusted CCI } & \multicolumn{4}{|l|}{ CCI } \\
\hline & $B$ & $P$ & Beta & $95 \% \mathrm{CI}$ & $B$ & $P$ & Beta & $95 \% \mathrm{CI}$ \\
\hline Length of hospital stay & 0.938 & 0.004 & 0.096 & $0.297-1.580$ & 1.659 & 0.000 & 0.129 & $0.814-2.503$ \\
\hline \multirow[t]{3}{*}{ Hospital expenses } & 1384.695 & 0.029 & 0.074 & $145.561-2623.829$ & 2963.144 & 0.000 & 0.120 & $1336.728-4589.561$ \\
\hline & \multicolumn{4}{|c|}{ Osteoprosis } & \multicolumn{4}{|c|}{ Hypertension } \\
\hline & $B$ & $P$ & Beta & $95 \% \mathrm{CI}$ & $B$ & $P$ & Beta & $95 \% \mathrm{CI}$ \\
\hline Length of hospital stay & 14.229 & 0.073 & 0.060 & $13.017-15.441$ & 2.339 & 0.012 & 0.930 & $0.513-4.164$ \\
\hline Hospital expense & 4811.431 & 0.007 & 0.090 & 1290.779-8332.084 & 5822.974 & 0.001 & 0.109 & 2319.887-9326.061 \\
\hline
\end{tabular}

CCI Charlson Comorbidity Index, CI confidence interval

average age-adjusted CCI. The last reason was the high proportion of patients with CCI in the range of $0-2$.

Several strengths of the present study should be noted. Identification of the weight of patients' comorbidities may have been an important contributor to the delay in surgery when the surgeons were unavailable. A study conducted by Gretchen M. Oroszfor quantified the time interval between injury and hospitalization in older patients with hip fracture [25]; they found that it was common to delay surgery by more than $24 \mathrm{~h}$ from hospitalization [25]. In some cases, the delay was related to patients themselves while in other cases the delay was attributed to systemic factors. Another strength is the assessment of the association of patients' comorbidities with the surgical procedure and perioperative management in geriatric patients with hip fracture, rather than collecting these information only from medical history. Lastly, the number of geriatric patients with hip fracture was large enough for conducting accurate evaluation of the relationship between comorbidities and treatment decision-making.

Surgical intervention in geriatric patients with hip fracture has been shown to decrease the risk of mortality up to 1 year, prevent progression to disability, and help maintain functional status of the patient [26-28]. Kau et al. [29] conducted a prospective cohort study of 212 geriatric patients (age $>60$ years) with hip fractures in Singapore. They observed that conservatively managed patients had higher CCI scores for mortality than surgically treated patients, which is consistent with our findings. Roubinian et al. [30] retrospectively evaluated the role of disease severity and comorbidity for predicting inpatient red blood cell transfusion events in 275,874 patients (444,969 hospitalizations); they found that disease severity and comorbidities play a limited role in predicting the likelihood of transfusion at the time of admission. Based on these observations, the incidence of transfusion relative to patient comorbidities in our study may be explained by inclusion of patients $>60$ years of age.

Several limitations of our study should be taken into account while interpreting the findings. First, the present study was a cross-sectional observational study; hence, the influence of confounding factors on our results cannot be ruled out. Secondly, there is lack of a unified comorbidity index for assessment of comorbidities in geriatric patients with hip fracture,[31] which may affect the reliability of our findings. We used the CCI and age-adjusted CCI, which is currently considered as the gold standard for assessment of comorbidity. In addition, complete data pertaining to treatment of comorbid conditions were not available; several studies have shown that the effectiveness of treatment of comorbidities affects the outcomes of elderly patients with hip fractures and the mean value of CCI was lower with respect to the majority of these studies [32-34]. Therefore, further multicenter randomized controlled studies with complete data and a validated comorbidity index are required to solve the aforementioned issues.

\section{Conclusion}

In this study, comorbidities were positively associated with the surgical procedure and perioperative management in elderly patients with hip fracture.

Author contributions Study concept and design: QD, ZX. Acquisition of data: JW, FL, SL. Analysis and interpretation of data: LZ, JW. Drafting of the manuscript: LZ, QD. Critical revision of the manuscript for important intellectual content: QD.

Funding This research did not receive any funding agencies in the public, commercial, or not-for-profit sectors.

Data Availability The datasets generated during and/or analysed during the current study are available from the corresponding author on reasonable request.

\section{Compliance with ethical standards}

Conflict of interest The authors declare no conflicts of interest. 
Statement of human rights The study was approved by the Biomedical Ethics Committee of the West China Hospital of Sichuan University.

Informed consent Written informed consent was obtained from all subjects.

OpenAccess This article is distributed under the terms of the Creative Commons Attribution 4.0 International License (http://creativeco mmons.org/licenses/by/4.0/), which permits unrestricted use, distribution, and reproduction in any medium, provided you give appropriate credit to the original author(s) and the source, provide a link to the Creative Commons license, and indicate if changes were made.

\section{References}

1. Vasu BK, Ramamurthi KP, Rajan S et al (2018) Geriatric patients with hip fracture: frailty and other risk factors affecting the outcome. Anesth Essays Res 12:546-551

2. Sheehan KJ, Williamson L, Alexander J et al (2018) Prognostic factors of functional outcome after hip fracture surgery: a systematic review. Age Ageing 47:661-670

3. Hoang-Kim A, Busse JW, Groll D et al (2014) Co-morbidities in elderly patients with hip fracture: recommendations of the ISFRIOF hip fracture outcomes working group. Arch Orthop Trauma Surg 134:189-195

4. Cooper C, Campion G, Melton LJ III (1992) Hip fractures in the elderly: a world-wide projection. Osteoporos Int 2:285-289

5. Liu SK, Ho AW, Wong SH (2017) Early surgery for Hong Kong Chinese elderly patients with hip fracture reduces short-term and long-term mortality. Hong Kong Med J 23:374-380

6. Maxwell MJ, Moran CG, Moppett IK (2008) Development and validation of a preoperative scoring system to predict 30 day mortality in patients undergoing hip fracture surgery. Br J Anaesth 101:511-517

7. Mosk CA, Mus M, Vroemen JP et al (2017) Dementia and delirium, the outcomes in elderly hip fracture patients. Clin Interv Aging 12:421-430

8. Trpeski S, Kaftandziev I, Kjaev A (2013) The effects of time-tosurgery on mortality in elderly patients following hip fractures. Pril (Makedon Akad Nauk Umet Odd Med Nauki) 34:115-121

9. Moja L, Piatti A, Pecoraro V et al (2012) Timing matters in hip fracture surgery: patients operated within 48 hours have better outcomes. A meta-analysis and meta-regression of over 190,000 patients. PLoS One 7:e46175

10. Tan ST, Tan WP, Jaipaul J et al (2017) Clinical outcomes and hospital length of stay in 2756 elderly patients with hip fractures: a comparison of surgical and non-surgical management. Singap Med J 58:253-257

11. Leung F, Lau TW, Kwan K et al (2010) Does timing of surgery matter in fragility hip fractures? Osteoporos Int 21:S529-S534

12. Sanz-Reig J, Salvador Marin J, Perez Alba JM et al (2017) Risk factors for in-hospital mortality following hip fracture. Rev Esp Cir Ortop Traumatol 61:209-215

13. Lau TW, Fang C, Leung F (2016) Assessment of postoperative short-term and long-term mortality risk in Chinese geriatric patients for hip fracture using the Charlson comorbidity score. Hong Kong Med J 22:16-22

14. Charlson ME, Pompei P, Ales KL et al (1987) A new method of classifying prognostic comorbidity in longitudinal studies: development and validation. J Chronic Dis 40:373-383

15. Charlson M, Szatrowski TP, Peterson J et al (1994) Validation of a combined comorbidity index. J Clin Epidemiol 47:1245-1251

16. Dauphinot V, Ravier A, Novais T et al (2016) Relationship between comorbidities in patients with cognitive complaint and caregiver burden: a cross-sectional study. J Am Med Dir Assoc 17:232-237

17. Orosz GM, Magaziner J, Hannan EL et al (2004) Association of timing of surgery for hip fracture and patient outcomes. JAMA 291:1738-1743

18. Bottle A, Aylin P (2006) Mortality associated with delay in operation after hip fracture: observational study. BMJ 332:947-951

19. Grimes JP, Gregory PM, Noveck H et al (2002) The effects of time-to-surgery on mortality and morbidity in patients following hip fracture. Am J Med 112:702-709

20. Simunovic N, Devereaux PJ, Sprague S et al (2010) Effect of early surgery after hip fracture on mortality and complications: systematic review and meta-analysis. CMAJ 182:1609-1616

21. Mak JC, Cameron ID, March LM (2010) Evidence-based guidelines for the management of hip fractures in older persons: an update. Med J Aust 192:37-41

22. Scottish Intercollegiate Guidline Network (2009) Management of hip fracture in older people. A national clinical guideline

23. Sanz-Reig J, Salvador Marin J, Ferrandez Martinez J et al (2017) Risk-factors for surgical delay following hip fracture. Rev Esp Cir Ortop Traumatol 61:162-169

24. Librero J, Peiro S, Leutscher E et al (2012) Timing of surgery for hip fracture and in-hospital mortality: a retrospective populationbased cohort study in the Spanish National Health System. BMC Health Serv Res 12:15

25. Orosz GM, Hannan EL, Magaziner J et al (2002) Hip fracture in the older patient: reasons for delay in hospitalization and timing of surgical repair. J Am Geriatr Soc 50:1336-1340

26. Wong MK, Ching LK, Lim SL et al (2002) Osteoporotic hip fractures in Singapore-costs and patient's outcome. Ann Acad Med Singap 31:3-7

27. Lin KH, Lim YW, Wu YJ et al (2005) Mortality after proximal hip fracture in the Singapore population. Hip Int 15:166-170

28. Lee AY, Chua BS, Howe TS (2007) One-year outcome of hip fracture patients admitted to a Singapore hospital: quality of life post-treatment. Singap Med J 48:996-999

29. Kau CY, Kwek EB (2014) Can preoperative scoring systems be applied to Asian hip fracture populations? Validation of the Nottingham Hip Fracture Score (NHFS) and identification of preoperative risk factors in hip fractures. Ann Acad Med Singap 43:448-453

30. Roubinian NH, Murphy EL, Swain BE et al (2014) Predicting red blood cell transfusion in hospitalized patients: role of hemoglobin level, comorbidities, and illness severity. BMC Health Serv Res $14: 213$

31. Harboun M, Ankri J (2001) Comorbidity indexes: review of the literature and application to studies of elderly population. Rev Epidemiol Sante Publique 49:287-298

32. Karres J, Heesakkers NA, Ultee JM et al (2015) Predicting 30-day mortality following hip fracture surgery: evaluation of six risk prediction models. Injury 46:371-377

33. Sanz-Reig J, Salvador Marin J, Ferrandez Martinez J et al (2018) Prognostic factors and predictive model for in-hospital mortality following hip fractures in the elderly. Chin J Traumatol 21:163-169

34. Wang X, Zhao BJ, Su Y (2017) Can we predict postoperative complications in elderly Chinese patients with hip fractures using the surgical risk calculator? Clin Interv Aging 12:1515-1520

Publisher's Note Springer Nature remains neutral with regard to jurisdictional claims in published maps and institutional affiliations. 